\title{
Patient's Satisfaction with Health Care Services in Erbil City/Iraq
}

Dlzar Omer Qadir; Department of Nursing, College of Nursing, Hawler Medical University, Erbil, Iraq.

Saleem Saaed Qader; Department of Kurdistan Board of Medical Specialties, Erbil, Iraq.

Dara Abdulla Al-Banna; Department of Nursing, College of Nursing, Hawler Medical University, Erbil, Iraq.

Ahmed Ali Rasool; College of Dentistry, Hawler Medical University, Erbil, Iraq.

Jamal Kareem Shakor; Nursing Department, Sulaimani Polytechnic University, Sulaymaniyah, Iraq

(Correspondence: jamal.shakor@spu.edu.iq)

\section{ABSTRACT}

Background and objective: Patient satisfaction is one of the most important factors to determine the success of a health care facility. It is a relative phenomenon, which evaluates the patients' perceived needs, their expectations from a health system, and the experience of health care. Patient satisfaction is the main goal today for most health care organizations, from hospitals to physician practices and other health care agencies. This study aimed to compare patient satisfaction with the health care services provided by public and private hospitals in Erbil City.

Methods: A cross-sectional study was conducted using a non-probability purposive sample of 450 patients ( 225 from public and 225 from private hospitals) who were seeking health care in hospitals in Erbil City. The data were collected between the 7th of January and 15th of November 2016 by direct interviews and filling of the standardized questionnaires (Patient Satisfaction Questionnaire-18).

Results and Discussion: Most of the patients in public hospitals expressed a neutral level of satisfaction with received health services (80.9\%) while $10.7 \%$ were dissatisfied and only $8.4 \%$ were satisfied with the provided health care. On the contrary, most of the patients in private hospitals (80\%) were satisfied with their care, with only $20 \%$ expressing a neutral level of satisfaction with private health care services. These findings show that there is a very high statistical difference between patient satisfaction in the governmental and private hospitals in Erbil City (Mean \pm Standard Deviation $45.35 \pm 3.520)$, (56.42 \pm 5.696$)$ (pvalue $=<0.001$ ).

Conclusion: Most of the patients were satisfied with private health care services but not with public hospitals health services in selected hospitals in Erbil City in Iraq.

Keywords: Patient satisfaction; Health care services; Governmental; Public and Private hospitals.

Received: 13/4/2020

Accepted:19/7/2020

Published: 30/11/2020

\section{INTRODUCTION}

Patient satisfaction with health care providers is of great significance. Thus, it is important to identify weaknesses in the health system, through the patient's eyes, to improve the quality of provided care[1]. Awareness has grown of how patients perceive the quality of their care. Patient satisfaction has become a tool to gain attention and value among the patients as well as providers. Hospitals and other health care centres are increasingly using this information while making important decisions regarding the operational and treatment plans [2]. The patient satisfaction data is the key indicator of the quality of care and treatment delivered 
by the physicians, other health staff and the hospital as a whole. The health centres can use survey results to design and track quality improvement over time, as well as compare themselves to other health centres [3]. By conducting their own surveys, the health care organizations can recognize and resolve potential patient satisfaction problems and thus improve their future strategies. Having satisfaction surveys also helps to identify the specific needs of the patients for the health care providers [4]. Hospitals that are committed to providing excellent health care services, including patient satisfaction, establish multiple programs and initiatives to achieve these goals. Measuring performance is essential to assessing the effects of continuous efforts to improve the quality of care and ensuring the pursuit of excellence in hospitals [5]. Increasingly, patient satisfaction is acknowledged as a key organizational performance measure. In addition to providing a unique perspective on the performance of a hospital, patient satisfaction is considered as a predictor of a patient's willingness to follow treatment, to return, or to recommend a service to others e.g. friends or relatives [6]. Patient satisfaction has emerged as a critical outcome of medical care due to increasing emphasis on patients as consumers of services in the medical marketplace [7]. Improved patient care has become a priority for all health care service providers with the optimum objective of achieving a high degree of patient satisfaction [8] Patients' socioeconomic background influences their perception of health care services to various degree. A study in Korea has shown that low-income people were more satisfied with the university health service than the hospitals [10]. Similarly, high education is mostly associated with patient satisfaction [11]. This study aims to compare patient satisfaction with the health care services provided by public and private hospitals in Erbil City.

\section{METHODS}

The study was conducted in some public and private hospitals in Erbil City, Kurdistan Region, Iraq. Governmental hospitals were Rizgary, Maternity and Hawler Teaching Hospitals, and private hospitals including the Paky Hospital, Zheen International Hospital, and CMC Hospital. The hospitals were randomly selected according to their recognition and those with a high number of patients. A non-probability, convenience (purposive) sampling was used to obtain the representative sample according to inclusion criteria. In this study, 450 patients (225 from public and 225 from private hospitals) were recruited to the study. The study included patients of both genders, aged 18 years and over who had been admitted for more than 24 hours and agreed to participate in the study. The patients at the end stage of their life were excluded from the study. This study was approved by the Scientific and Ethics Committee of the College of Nursing, Hawler Medical University, Erbil, Iraq. Institutional approval for conducting the study in public hospitals was also obtained from the General Directorate of Health in Erbil. Formal permission to undertake the study in private facilities was attained directly from the hospital administrations. The study was explained to the patients in their native Kurdish language and the patients were told that they have the rights to withdraw from the study at any stage. The information about the patients was kept confidential throughout the study and afterwards. Each form for each patient was coded with a number. The patients were informed that in case of any interest achieved from the study in the future, they would have a right of free access to the health care provided by these 
hospitals for a certain period of time. Data were collected using a standardized questionnaire (short-form patient satisfaction questionnaire PSQ-18), which was developed by RAND Health Research Organization for medical outcomes study. The PSQ18 is a short-term version that retains many characteristics of its full-length counterpart. The PSQ sub-scales show acceptable internal consistency reliability. The questionnaire contains 18 items tapping each of the seven domains of satisfaction which includes: general satisfaction, technical quality, interpersonal manner, communication, financial aspects, time spent with doctors, and accessibility and convenience with some modifications. The responses contain both positively worded and negatively worded items, ranging from strongly agree to strongly disagree [7]. The method of data collection was through direct interview with each patient by researchers. The questionnaire was translated into the Kurdish language by the linguistic expert and fully explained to the patients. Statistical analysis The data were analysed using the Statistical Package for Social Sciences (SPSS, Version 23) application for statistical data analysis. Independent t-test was used to know the statistical difference in the mean of patient satisfaction in private and public hospitals.

RESULTS 450 patients (225 from public and 225 from private hospitals) who were seeking health care in Erbil City were recruited to this study. Concerning the sociodemographic characteristics, the highest percentage of the patients in both governmental and private hospitals were in the age group $19-32$ years ( $41.8 \%$ and $57.8 \%$ ), female in gender $(68.9 \%$ and $65.3 \%)$, graduated from secondary school $(24.4 \%$ and $30.2 \%)$, currently married $(87.1 \%$ and $83.6 \%)$, keeping house/homemaker (54.7\%
$52.4 \%)$, from the urban residential area (79.6\% and $73.8 \%)$ as demonstrated in Table 1.

Table 2 shows the overall level of patient satisfaction with health care services in both governmental and private hospitals. Most of the patients answered neutrally regarding the health care services in the governmental hospitals (80.9\%), while $10.7 \%$ of participants were dissatisfied and only $8.4 \%$ satisfied with health care services. Most of the patients in private hospitals were satisfied with the health care services they received $(80 \%)$, with only $20 \%$ of the patients being dissatisfied.

Table 3, shows a very high statistical difference between the mean of patient satisfaction in governmental and private hospitals ( $p$-value $=<0.001$ ) with 11.067 mean difference ( $\mathrm{M} \pm \mathrm{SD}$ of governmental hospitals $45.35 \pm 3.520$ and $56.42 \pm 5.696$ of private hospitals), which means that most patients were more satisfied with the private health services than with governmental health care. 
Table 1: Sociodemographic characteristics of the study sample

\begin{tabular}{|c|c|c|c|c|c|c|c|}
\hline \multicolumn{2}{|c|}{ Sociodemographic characteristics } & \multicolumn{4}{|c|}{ Hospital setting } & \multicolumn{2}{|c|}{ Total } \\
\hline & & \multicolumn{2}{|c|}{ Governmental } & \multicolumn{2}{|c|}{ Private } & \multirow[b]{2}{*}{ No. } & \multirow[b]{2}{*}{ (\%) } \\
\hline & & No. & (\%) & No. & (\%) & & \\
\hline \multirow[t]{5}{*}{ Age groups/years } & $19-32$ & 94 & $(41.8)$ & 130 & (57.8) & 224 & (50) \\
\hline & $33-46$ & 87 & (38.7) & 59 & $(26.2)$ & 146 & (32) \\
\hline & $47-60$ & 29 & (12.9) & 21 & (9.3) & 50 & (11) \\
\hline & $61-74$ & 15 & (6.7) & 15 & (6.7) & 30 & (7) \\
\hline & Total & 225 & (50) & 225 & (50) & 450 & $(100)$ \\
\hline \multirow[t]{3}{*}{ Gender } & Male & 70 & (31.1) & 78 & (34.7) & 148 & (30) \\
\hline & Female & 155 & (68.9) & 147 & $(65.3)$ & 352 & (70) \\
\hline & Total & 225 & $(50)$ & 225 & (50) & 450 & $(100)$ \\
\hline \multirow[t]{6}{*}{ Level of Education } & Illiterate & 32 & (14.2) & 21 & (9.3) & 53 & (12) \\
\hline & Can read and write & 38 & $(16.9)$ & 16 & $(7.1)$ & 54 & (12) \\
\hline & Primary school & 51 & (22.7) & 56 & (24.9) & 107 & (24) \\
\hline & Secondary school & 55 & (24.4) & 68 & $(30.2)$ & 123 & (27) \\
\hline & Institution or college & 49 & (21.8) & 64 & (28.4) & 113 & (25) \\
\hline & Total & 225 & $(50)$ & 225 & (50) & 450 & $(100)$ \\
\hline \multirow[t]{5}{*}{ Marital status } & Never married & 20 & (8.9) & 34 & (15.1) & 54 & (12) \\
\hline & Currently married & 196 & (87.1) & 188 & (83.6) & 384 & (85) \\
\hline & Divorced & 1 & $(0.4)$ & 2 & $(0.9)$ & 3 & (0) \\
\hline & Widowed & 8 & (3.6) & 1 & (0.4) & 9 & (2) \\
\hline & Total & 225 & (50) & 225 & (50) & 450 & (100) \\
\hline \multirow[t]{9}{*}{ Occupational status } & Paid work & 5 & (2.2) & 4 & (1.8) & 9 & (2) \\
\hline & Self-employed & 38 & (16.9) & 47 & (20.9) & 85 & (19) \\
\hline & (volunteer or charity) & 10 & $(4.4)$ & 11 & (4.9) & 21 & (5) \\
\hline & Student & 16 & (7.1) & 18 & (8.0) & 34 & (8) \\
\hline & Housewife & 123 & (54.7) & 118 & (52.4) & 241 & (57) \\
\hline & Retired & 4 & $(1.8)$ & 6 & (2.7) & 10 & (2) \\
\hline & $\begin{array}{l}\text { Unemployed (health } \\
\text { reason) }\end{array}$ & 20 & (8.9) & 8 & (3.6) & 28 & (6) \\
\hline & $\begin{array}{l}\text { Unemployed (other } \\
\text { reason) }\end{array}$ & 9 & (4) & 13 & (5.8) & 22 & (6) \\
\hline & Total & 225 & (50) & 225 & (50) & 450 & (100) \\
\hline \multirow[t]{3}{*}{ Residential area } & Urban & 179 & (79.6) & 166 & (73.8) & 345 & (77) \\
\hline & Rural & 46 & $(20.4)$ & 59 & $(26.2)$ & 105 & (23) \\
\hline & Total & 225 & (50) & 225 & $(50)$ & 450 & $(100)$ \\
\hline \multirow[t]{3}{*}{ Times of visit } & $1-4$ & 187 & (83.1) & 217 & (96.4) & 404 & (90) \\
\hline & $5-8$ & 38 & (16.9) & 8 & (3.6) & 46 & (10) \\
\hline & Total & 225 & (50) & 225 & (50) & 450 & (100) \\
\hline
\end{tabular}


Table 2: Overall level of satisfaction among patients visiting governmental and private hospitals

\begin{tabular}{|c|c|c|c|c|c|c|}
\hline \multirow[t]{3}{*}{ Overall level of satisfaction } & \multicolumn{3}{|c|}{ Hospital setting } & \multicolumn{3}{|c|}{ Total } \\
\hline & \multicolumn{2}{|c|}{ Governmental } & \multicolumn{2}{|l|}{ Private } & \multirow[b]{2}{*}{ No. } & \multirow[b]{2}{*}{ (\%) } \\
\hline & No. & (\%) & No. & (\%) & & \\
\hline Highly satisfied & 0 & (0) & 0 & (0) & 0 & (0) \\
\hline Satisfied & 19 & (8.4) & 180 & (80) & 199 & (44) \\
\hline Neutral & 182 & (80.9) & 45 & (20) & 227 & (50) \\
\hline Dissatisfied & 24 & $(10.7)$ & 0 & (0) & 24 & (5) \\
\hline Strongly dissatisfied & 0 & (0) & 0 & (0) & 0 & (0) \\
\hline Total & 225 & (50) & 225 & (50) & 450 & (100) \\
\hline
\end{tabular}

Table 3: Comparison between governmental and private hospitals regarding the patient's satisfaction

\begin{tabular}{lccccccc}
\hline Hospital setting & N & Mean & $\begin{array}{c}\text { Std. Devi- } \\
\text { ation }\end{array}$ & $\begin{array}{c}\text { Std. Error } \\
\text { Mean }\end{array}$ & t-value & Mean Difference & P-value \\
\hline Government & 225 & 45.35 & 3.520 & 0.235 & 24.79 & 11.067 & $<0.001$ \\
Private & 225 & 56.42 & 5.696 & 0.380 & & & \\
\hline
\end{tabular}

\section{DISCUSSION}

Patient satisfaction with health care provided by doctors and other health staff is of great importance. Thus, it is important to identify the weaknesses of the health system from the patients' perspective to improve and promote health care in the region [9]. This cross-sectional study was based upon direct interviews of 450 patients who received health care in public and private hospitals in Erbil City. Most of the patients were young in their $2 \mathrm{nd}$ and $3 r d$ decade (19-32 years) of their life (41.8\% in public versus $57.8 \%$ in private hospitals) and $33-46$ years $(38.7 \%$ in public versus $26.2 \%$ in private hospitals). The rest of the patients were above 47 years of age (19.6\% in public versus $16 \%$ in private hospitals). So, in the current study, young people attended private hospitals more than public hospitals while aged people were admitted to public hospitals more. In this study, there were $68.9 \%$ females, $14.2 \%$ were illiterate, while $85.8 \%$ graduated either from university $(21.8 \%)$ or secondary school, so most of the patient are aware of health services offered by the hospitals whether in private or public. $8.9 \%$ of the patients were single, $3.6 \%$ were widow, $38 \%$ were self-employed, $79.96 \%$ were living in the City of Erbil and $83.1 \%$ had 1 4 visits to the hospital. According to the current study, more educated people utilized private hospitals rather than governmental hospitals. High satisfaction in the private hospital might be related to sociodemographic factors such as age and education. There is another study that confirmed that the level of education is a predictor for patient satisfaction [11]. 
The level of satisfaction of the patients in the public facilities during their visit to the hospital was neutral in $80.9 \%, 10.7 \%$ of patients were dissatisfied and only $8.4 \%$ were satisfied with provided health services. In private hospitals, $80 \%$ of patients were satisfied and $20 \%$ gave a neutral response. Thus, this study has shown that health care in Erbil City differs between public and private hospitals. This finding is consistent with another study, which has shown the difference in the level of satisfaction seen in Korea where people mostly more prefer the university health system rather than hospitals [10]. Private hospitals have high levels of patient satisfaction and aim to continuously optimize health service provision. They always compete among themselves to attract patients locally and nationally. In some countries, medical tourism plays an important role in the economy of the country e.g. Jordan, Turkey, and India. Research studies have shown that patient satisfaction plays a major role in medical tourism, and patient satisfaction is unique to influence international medical tourists $[12,13]$. Currently, the private hospitals in Kurdistan play an important role in health care services and they help the public hospitals to decrease the burden on the government and provide many benefits for the patients and the society. Patients can get senior doctors and health care immediately at any time in private hospitals unlike in the public health sector [14]. A major barrier to private hospitals attendance is out-of-pocket costs as there is no health insurance system in the region for the people to use private hospitals and outpatient or consultant clinics services. Outpatient and hospital costs at the national level are not clear, but it is clear that they are high for the patients and their families e.g. in Australia out-ofpocket consultation costs to patients vary nationally (\$110-\$480) [15].

\section{CONCLUSION}

In Erbil City, the patients are more satisfied with the health care in private hospitals than in public hospitals. The government should improve the care provided in the public sector and strengthen the weaknesses in the health system.

\section{RECOMMENDATIONS}

Research and education about decisionmaking regarding the choice between public and private hospital attendance should be encouraged, and information about diseases and the way of management is critical in extending and improving the lives of people and decreasing the complications of diseases. The government should improve the health services to assimilate all the society's need and to encourage both public and private health insurance. Encouragement of private health insurance in the region is very important to decrease the out-ofpocket expenses for the patients. Patient satisfaction is an important tool to assess the quality of health care and to encourage medical tourism from the rest of Iraq in the near future and from the neighboring countries in the long term.

\section{CONFLICT OF INTEREST}

The author declares no conflicts of interest. The authors' involvement in the study is reflected in the order of their names.

\section{REFERENCES}

[1] Thayaparan AJ, Mahdi E. The Patient Satisfaction Questionnaire Short Form (PSQ-18) as an adaptable, reliable, and validated tool for use in various settings. Medical Education Online. 2013, 18:21747.

[2] Crow R, Gage H, Hampson S, Hart J, Kimber A, Storey $L$, et al. The measurement of satisfaction with healthcare: 
implications for practice from a systematic review of the literature.; Health Technological Assess. 2002, 6 (32):1-244.

[3] Bergenmar $M$, Nylen U, Lidbrink E, Bergh J, Brandberg Y. Improvements in patient satisfaction at an outpatient clinic for patients with breast cancer. Acta Oncologica, 2006. 45 (5):550-8.

[4] Lis CG, Rodeghier M, Grutsch JF, Gupta D. Distribution and determinants of patient satisfaction in oncology with a focus on health-related quality of life. BMC Health Serves Research. 2009; 9:190.

[5] Freeman T. Using performance indicators to improve health care quality in the public sector: a review of the literature. Health Serves Manage Research. 2002; 15 (2):12637.

[6] Kone Pefoyo AJ, Wodchis WP. Organizational performance impacting patient satisfaction in Ontario hospitals: a multilevel analysis. BMC Research Notes. 2013; 6:509.

[7] RAND Health Care. Patient Satisfaction Questionnaire from RAND Health. Douglas Aircraft Company of Santa Monica, California. (Accessed on 29 April 2015). Available from: http://www.rand.org/health/ surveys_tools/psq.html.

[8] Faiza Manzoor, Longbao Wei, Abid Hussain, Muhammad Asif, and Syed Irshad Ali Shah. Patient Satisfaction with Health Care Services; An Application of Physician's Behavior as a Moderator. International Journal of Environmental Research and Public Health. Sep 2019; 16(18): 3318 . Available from: https://www.ncbi.nlm.nih.gov/pmc/ articles/PMC6765938/

[9] Anthony Janahan Thayaparan and Eamon Mahdi. The Patient Satisfaction Questionnaire Short Form (PSQ-18) as an adaptable, reliable, and validated tool for use in various settings. Medical Education Online 2013. 18: 10.3402/meo.v18i0.21747.

[10] Cho Y, Chung H, Joo H, Park HJ, Joh H-K, Kim $J W$, et al. Comparison of patient perceptions of primary care quality across healthcare facilities in Korea: A cross-sectional study. (2020), PLOS ONE 15(3): e0230034. https:// doi.org/10.1371/journal.pone.0230034

[11] Macki M, Alvi MA, Kerezoudis P, Xiao S, Schultz L, Bazydlo $M$, et al. Predictors of patient dissatisfaction at 1 and 2 years after lumbar surgery. Journal of Neurosurgery. 2019 Nov 22:1-10. DOI: 10.3171/2019.8 SPINE19260.
[12] Park, JungKun; Ahn, Jiseon; Yoo, Weon Sang, The Effects of Price and Health Consciousness and Satisfaction on the Medical Tourism Experience. Journal of Healthcare Management. 2017, 62(6):405-417, November/December.

[13] Kim, Minseong. "From Servicescape to Loyalty in the Medical Tourism Industry: A Medical Clinic's Service Perspective." Inquiry: Journal Of Medical Care Organization, Provision And Financing. (2017): vol. 54:46958017746546.DOI:10.1177/004695 8017746546

[14] Karadaghi G, Willott C. Doctors as the governing body of the Kurdish health system: exploring upward and downward accountability among physicians and its influence on the adoption of coping behaviours. Human Resources for Health (2015) 13:43. DOI: 10.1186/s12960-015-0039-x.

[15] Katherine Walker, Michael Ben-Meir. Choosing public or private emergency departments in Australia. Emergency Medicine Australasia. 2017 https:// doi.org/10.1111/1742-6723.12879). 